\section{Mechanical Shearing Device for Potted Rosemary Christmas Tree Topiaries}

\author{
Daniel F. Warnock ${ }^{1}$
}

Additional INDEX WORDS. Rosemarinus officinalis, niche market crops, greenhouse herb production, topiary shaping, electric shears

Summary. Greenhouse production of rosemary (Rosemarinus officinalis) as small potted Christmas-tree topiaries for holiday sales have become necessary for many companies marketing to large retail outlets. Topiaries must be sheared multiple times to obtain an acceptable Christmas-tree shape. Most production greenhouses use hand pruning shears or hand-held cordless grass shears to shape topiaries free hand or with the aid of a template. Crop size and uniformity can vary with these shearing methods. To create a more uniform rosemary Christmastree topiary for cultivar evaluations, a mechanical shearing device constructed from over-the-counter parts was developed at the University of Illinois. A detailed description of the design and construction of this mechanical shearing device is presented in this report.

$\mathrm{R}$ osemary, a common garden herb grown in many regions of the vorld, has culinary, medicinal, and aesthetic uses (Voigt, 2000). Various ethnic groups enhance food and beverage flavors through the addition of rosemary leaves. In folk medicine, rosemary is used to relieve respiratory disorders and to stimulate hair growth (Sereiti et al., 1999). More recently the medicinal properties of rosemary, including anticancer activities, were attributed to chemical compounds found in the essential oil (Sereiti et al., 1999; Soulier et al., 1996). In folklore, rosemary is often associated with Christmas and was spread on floors during the holiday season to expel evil spirits. A re-

\footnotetext{
The author thanks Green Leaf Perennials (Lancaster, Pa.) for the donation of plants.

${ }^{1}$ Assistant professor, University of Illinois, Department of Natural Resources and Environmental Sciences, 1201 South Dorner Dr., Urbana, IL 61801. To whom reprint requests should be addressed; e-mail dwarnock@uiuc.edu.
}

cent resurgence of rosemary popularity during the Christmas season has created specific challenges for commercial herb producers.

Outdoor production of rosemary for culinary and medicinal purposes is well documented (Bolelens, 1985; Soulier et al., 1996). The production of rosemary in commercial greenhouses can be challenging due to insect and disease pressures combined with the need for tight water management (De Baggio, 1987; Long, 1998). Rosemary plants produced in greenhouses mainly are used as fresh cut herbs or bedding plants for transplanting into the home landscape (Long, 1998). Rosemary topiaries, while commonly grown by homeowners, are less often produced in commercial facilities due to the increased labor and time needed to create these sculpted plants. One exception to this is Christmas-tree-shaped topiaries.

Current production practices for rosemary Christmas-tree topiaries vary by grower, but commonly involve shearing the plants several times with hand-held devices to obtain the Christmas-tree shape (De Baggio, 1987). Commercially produced woody Christmas trees have a $40 \%$ to $90 \%$ taper with a 66\% taper being ideal (Brown et al., 1991). For potted topiaries, crop uniformity is essential and most producers target a $60 \%$ to $70 \%$ taper (C.E. Voigt, personal communication). To ensure that appropriately shaped rosemary topiaries are obtained, growers may use templates with a 10 to $20^{\circ}$ angle as a guide for the shearing device. Hand shearing with templates unfortunately is time consuming and final topiary shape can vary by operator. To create a more uniform rosemary Christmas-tree topiary for cultivar evaluations, a mechanical shearing device was constructed from over-the-counter parts. The objective of this manuscript is to provide growers with a detailed description of the design, construction, and use of this mechanical shearing device.

\section{Construction}

The shearing device is comprised of four main units joined together to create an adjustable assembly suitable for shearing plants in pots ranging in size up to 7 inches $(17.8 \mathrm{~cm})$ diameter. The four units are an adjustable turntable, an adjustable shearing unit, a base, and a safety guard. Table l presents a materials list for the units. A general view of the completed shearing device with safety guard, without safety guard, and from the reverse side is presented in Fig. la, $\mathrm{b}$, and c, respectively.

Adjustable turntable. Drill a 0.06 -inch hole $(1.0$ inch $=2.54 \mathrm{~cm})$ through each wood base (B and D) at the center point as determined by drawing diagonal lines from corner to corner. Attach wood base (B) to the top of the lab-jack (A) using four wood screws $(\mathrm{X})$. Wood base $(\mathrm{D})$ is attached to the top of the lazy susan bearing $(\mathrm{C})$ with four wood screws $(\mathrm{X})$. After using the pilot holes to align the wooden bases, attach $\mathrm{C}$ to $\mathrm{B}$ with four wood screws (X). Drill a 0.06-inch pilot hole at the center of the wood circle (E) and the rubber pad (F). Being careful to align the pilot holes, glue $\mathrm{E}$ and $\mathrm{F}$ together using carpenter's adhesive to make a turntable top. Attach the turntable top to $\mathrm{D}$ using a fender washer $(\mathrm{V})$ and wood screw $(\mathrm{W})$. A large diameter wood circle and rubber pad combination can replace the small turntable top when larger pots are being sheared.

Adjustable Shearing UnIt. Trim the wood connector plate $(\mathrm{J})$ bottom to fit the overhead projector arm and focus assembly $(\mathrm{G})$ support bracket. For the support bracket used in the current example, a $60^{\circ}$ angle was needed along the base of J. A 7-inch cut (labeled A) at a $15^{\circ}$ angle was made beginning 0.8 inch below the top right corner of $\mathrm{J}$ using a 0.13-inch-wide saw blade (Fig. 2). A parallel 4.6-inch cut was made beginning 1.6 inch to the left of the upper right hand corner (17.7-inch edge) of $\mathrm{J}$ (Fig. 2). Beginning 4.4 inches below the upper left hand corner of J, a 2.4inch cut was made perpendicular to the 10.4-inch edge to obtain the connector plate shape seen in Fig. 2. To allow for heat exchange and ventilation during operation of the electric hedge trimmer $(\mathrm{H})$, a single $0.8 \times 3.7$-inch hole was cut (labeled D) along a $15^{\circ}$ angle beginning 10.2 inches from the 1.6-inch top edge and 2 inches from the 17.7-inch edge of $\mathrm{J}$. To allow mounting of $\mathrm{H}$, three 0.37 -inch holes (labeled B) were drilled through $J$ at $10.4,9.5$, and 6.5 inches from the 1.6-inch top edge and 3.6, 0.6, and 2.6 inches from the 17.7-inch edge, respectively (Fig. 2). Temporarily attach $\mathrm{H}$ to $\mathrm{J}$ by inserting three hex head bolts (S) through $\mathrm{J}$ into the three 0.31 -inch holes in the molded body of $\mathrm{H}$ and gently tighten until snug. To keep the electric trimmer blade parallel with $\mathrm{J}$, a wood shim may be attached to J. Secure $\mathrm{H}$ to $\mathrm{J}$ with nylon straps (I), four fender 
Table 1. Over-the-counter components needed to construct a mechanical shearing device for small potted topiaries.

\begin{tabular}{|c|c|c|}
\hline Item & Quantity & Description $^{\mathrm{z}}$ \\
\hline \multicolumn{3}{|c|}{ Adjustable turntable } \\
\hline A & 1 & Lab-jack (5.9 × 5.9-inch platform; Fischer Scientific, Pittsburgh, Pa.) \\
\hline $\mathrm{B}$ & 1 & Wood base, $0.4 \times 5.9 \times 5.9$ inches \\
\hline $\mathrm{C}$ & 1 & Lazy susan bearing, 4.0 inches \\
\hline $\mathrm{D}$ & 1 & Wood base, $0.4 \times 3.9 \times 3.9$ inches \\
\hline $\mathrm{E}$ & 1 & Wood circle, $0.2 \times 6.3$ inches diameter \\
\hline $\mathrm{F}$ & 1 & Rubber pad, $0.2 \times 5.9$ inches diameter \\
\hline \multicolumn{3}{|c|}{ Adjustable shearing head } \\
\hline G & 1 & Overhead projector arm and focus assembly \\
\hline $\mathrm{H}$ & 1 & 16.0-inch electric hedge trimmer (model TRl65; Black and Decker, Inc., Towson, Md.) \\
\hline I & 2 & Nylon straps, $1.0 \times 13.4$ inches \\
\hline $\mathrm{J}$ & 1 & Wood connector plate, $1.0 \times 5.1 \times 17.7$ inches \\
\hline \multicolumn{3}{|r|}{ 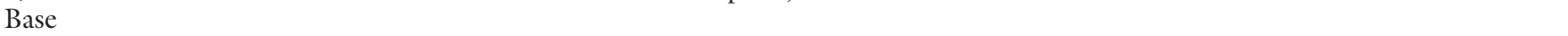 } \\
\hline K & 1 & Wood base, $0.8 \times 12.2 \times 22.0$ inches \\
\hline $\mathrm{L}$ & 2 & 16.5-inch center-mount drawer slides and hardware \\
\hline M & 1 & Wood base, $0.6 \times 10.0 \times 16.7$ inches \\
\hline \multicolumn{3}{|c|}{ Safety guard } \\
\hline $\mathrm{N}$ & 1 & Clear plexiglass sheet, $24.0 \times 48.0$ inches \\
\hline $\mathrm{O}$ & 1 & Solid angle aluminum, $0.06 \times 0.75 \times 90.0$ inches \\
\hline $\mathrm{P}$ & 1 & Vinyl mat, $0.1 \times 15.0 \times 17.7$ inches \\
\hline \multicolumn{3}{|c|}{ Hardware } \\
\hline Q & 3 & "L" brackets, 2.0 inches \\
\hline $\mathrm{R}$ & 1 & "T" bracket, 3.0 inches \\
\hline$S$ & 3 & Hex head bolts, $0.3 \times 3.0$ inches \\
\hline $\mathrm{T}$ & 2 & Hex head bolts, $0.3 \times 1.5$ inch \\
\hline $\mathrm{U}$ & 2 & Stop nuts with nylon insert, 0.3 inch \\
\hline $\mathrm{V}$ & 5 or 6 & Fender washers, $0.25 \times 1.25$ inch \\
\hline W & 17 & no. $10 \times 0.5$ inch wood screws \\
\hline $\mathrm{X}$ & 12 & no. $6 \times 0.25$ inch wood screws \\
\hline $\mathrm{Y}$ & 11 & no. $8 \times 0.5$ inch self-drilling screws \\
\hline $\mathrm{Z}$ & 80 & no. $6 \times 0.5$ inch flat-head bolts \\
\hline AA & 80 & no. 6 stop nuts with nylon insert \\
\hline $\mathrm{BB}$ & 4 & Rubber feet with hardware, $0.2 \times 0.6$ inch diameter \\
\hline
\end{tabular}

${ }^{{ }^{1}} 1.0$ inch $=2.54 \mathrm{~cm}$.

washers $(\mathrm{V})$, and four wood screws (W) guided by 0.06 -inch pilot holes (labeled E, Fig. 2). Remove H from J. Attach $\mathrm{J}$ to the overhead projector assembly bracket with two hex head bolts (T) and stop nuts (U) after drilling two 0.37-inch holes (labeled C) through

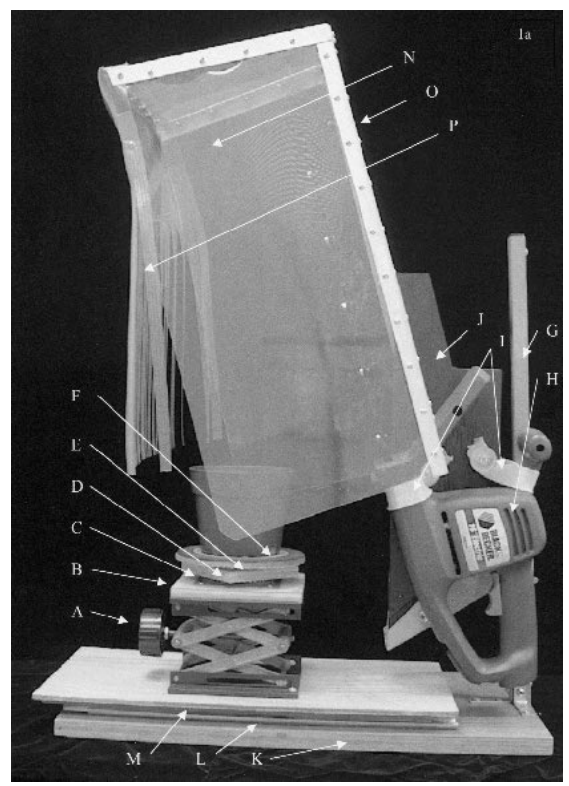

the assembly bracket and J (Fig. 2). A wood shim may be necessary to ensure a tight fit of J within the bracket.

BASE. Using the hardware provided by the manufacturer, attach four rubber feet (BB) to the underside of $\mathrm{K}$ equal distance from each corner. Attach the center mount drawer slides (L) with the hardware provided by the manufacturer to the underside of wood base

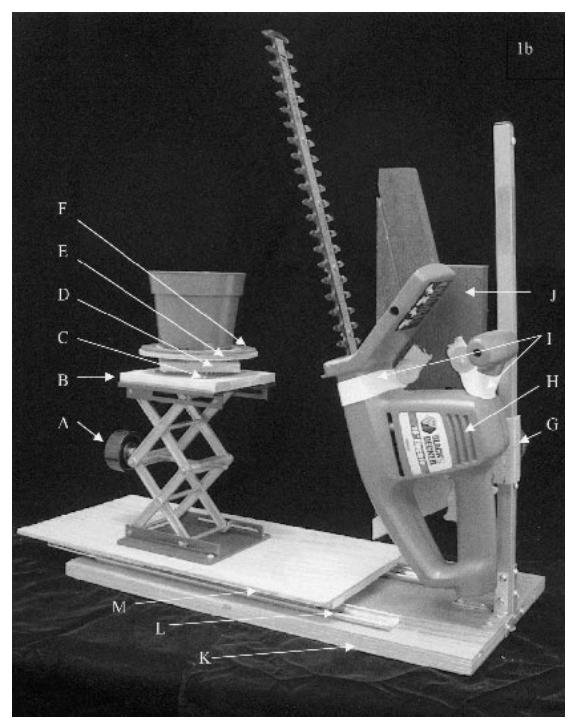

(M). To operate properly and increase stability during use, the slides $(\mathrm{L})$ should run parallel to one another and each centered 1.6 inch from the 16.7-inch edge of $\mathrm{M}$. To ensure that the shearing

Fig. 1. A general view of a completed shearing device for small potted topiaries constructed from over-the-counter components with safety guard (a), without safety guard (b), and from the reverse side $(c)$.

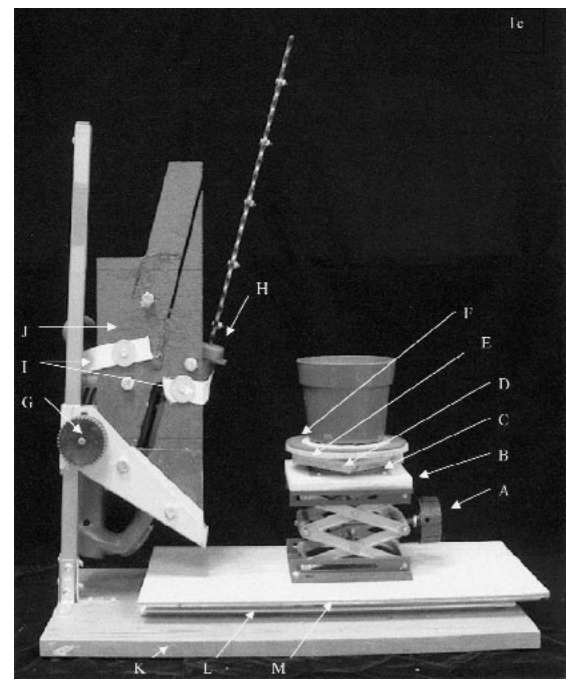




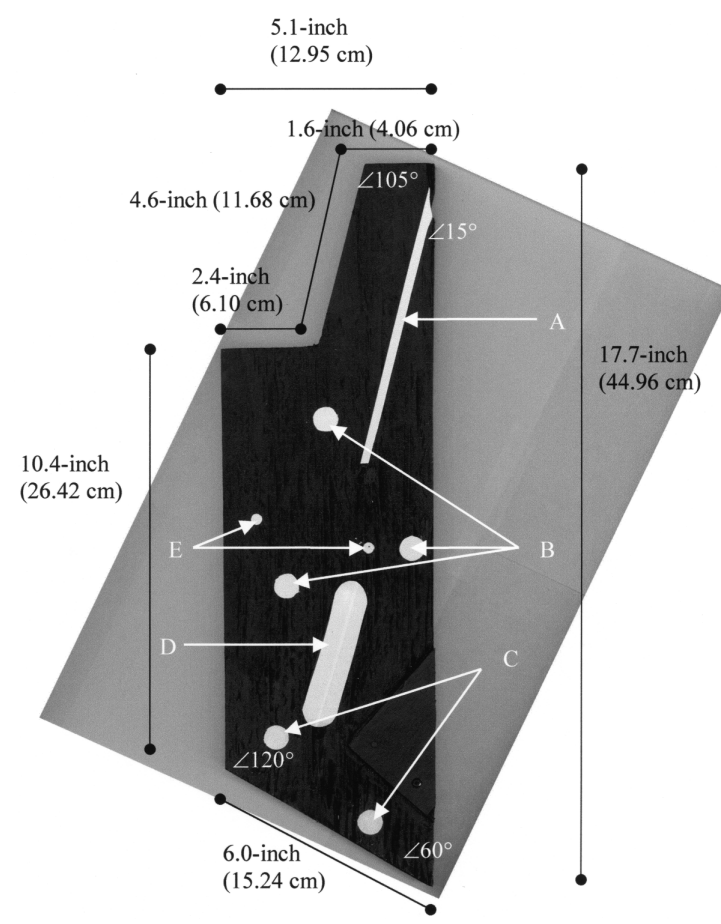

Fig. 2. Construction of a wood connector plate $(\mathrm{J})$ used to attach the electric hedge trimmer $(\mathrm{H})$ to the overhead projector arm and focus assembly (G) of a shearing device for small potted topiaries. Final dimensions of the connector plate are presented in black text and lines. Lettered arrows A through $\mathrm{E}$ indicate interior cuts and holes. Angles of critical corners and cuts are indicated in white.

process can be accomplished, the adjustable turntable and the shearing assembly must be offset. When attaching $\mathrm{M}$ to $\mathrm{K}$, L should be fully extended, placed 4.1 inches from one 12.2-inch end of $\mathrm{K}$, and centered 1.4 and 8.1 inches from one 22.0-inch edge of $\mathrm{K}$. Check to be sure that L operates correctly and adjust to obtain a smooth sliding action.

SAFETY GUARD. The clear plexiglass sheet $(\mathrm{N})$ is cut into four pieces; two $10.2 \times 21.3$-inch sides, one $6.4 \times 21.3$ inch top, and one trapezoid with a 6.4 , 13.0, and 9.8-inch top, base and sides, respectively. The solid angle aluminum $(\mathrm{O})$ is cut into 21.3-, 21.3-, 13.4-, 10.6-, 10.6-, and 6.5-inch-length pieces. Fit the $13.4,10.6$, and 6.5-inch pieces together to form a trapezoid. Trim the junctions to obtain a tight fit at each corner. Temporarily attach the pieces together by drilling 0.13-inch holes through $\mathrm{O}$ at each junction and inserting flat head bolts $(Z)$ and stop nuts (AA). Slightly spread the angle of the 21.3-inch pieces by placing the aluminum open angle down on a flat surface and gently tapping with a hammer. Connect the two 21.3-inch pieces to the previously constructed trapezoid frame with $\mathrm{Z}$ and AA. Smooth all corners and joints to prevent worker injury. Starting with the $6.4 \times 21.3$-inch plexiglass top, individually attach the plexiglass pieces to the frame by drilling 0.13 -inch holes through $\mathrm{O}$ and $\mathrm{N}$ on 2 inch centers, inserting $\mathrm{Z}$, and securing with AA. Holes on opposite sides of a single piece of $\mathrm{O}$ should be offset by 1.0 inch to allow proper securing with AA.

Remove the 13.4-inch piece of $\mathrm{O}$ from the frame. Cut 11.8-inch vertical slits every 0.4 inch in the vinyl mat $(\mathrm{P})$, beginning each cut 5.9 inches below one 15.0inch edge. Center the uncut 15.0-inch edge of $\mathrm{P}$ on the plexiglass trapezoid base. Reattach the 13.4-inch frame piece securing $\mathrm{P}$ between the plexiglass and frame. Drill 0.13-inch holes through $P$ using the existing holes in $\mathrm{O}$ and $\mathrm{N}$ as guides, insert $\mathrm{Z}$, and secure with $\mathrm{AA}$. Wrap the excess $\mathrm{P}$ around either side of the safety guard and secure to the plexiglass sides with $\mathrm{Z}$ and AA.

FINAL ASSEMBLY. Drill a 0.8 -inchdiameter hole centered 6.1 inches from the side and 0.5 inch from the 12.2-inch edge of wood base (K) not covered by $M$ when drawer slides (L) are closed. Attach $\mathrm{G}$ to $\mathrm{K}$ by removing the base washer and set screw from $G$, inserting the overhead projector arm through the drilled hole in $\mathrm{K}$, and replacing the base washer and set screw. If needed, an additional fender washer $(\mathrm{V})$ between the base washer and setscrew may be used to ensure a tight seal. Turn the focus knob down until the assembly bracket rests snuggly against $\mathrm{K}$. Plumb $\mathrm{G}$ and secure to $\mathrm{K}$ with three $\mathrm{L}$ brackets $(\mathrm{Q})$ and one $\mathrm{T}$ bracket $(\mathrm{R})$ using eight wood screws $(\mathrm{W})$ and nine self drilling screws $(\mathrm{Y})$ for wood and metal connections, respectively.

Place the adjustable turntable unit on M so that the height adjustment knob on A is opposite G. The base of A should be positioned on M 1.4 inch from the 16.7-inch edge of $M$ that is vertically flush with Kand 5.9 inches from the 10.0-inch edge of $\mathrm{M}$ that is vertically flush with $\mathrm{K}$ when the drawer slides (L) are closed. Secure adjustable turntable unit to $\mathrm{M}$ using four wood screws (W).

Reassemble the adjustable shearing unit. Lower the shearing unit until the base of $\mathrm{H}$ is 1.2 inch above $\mathrm{K}$. Note where the bracket of $\mathrm{G}$ is located on the projector arm. Insert a self-drilling screw (Y) below the focus knob bracket as a lower stop for the shearing unit. Y should be placed directly above the $\mathrm{T}$ bracket. Place a second Y 0.8 inch below the top of the projector arm as an upper stop for the shearing unit. Carefully slide the safety guard into the 0.13 -inch-wide slot in J until touching $\mathrm{H}$. Mark where plexiglass $(\mathrm{N})$ touches $\mathrm{H}$ and remove enough $\mathrm{N}$ to allow the safety guard to completely enclose the shearing blade. To reinforce $\mathrm{N}$, a $0.5 \times 6.5$-inch piece of flat aluminum may be attached along the upper edge of the notch using $\mathrm{Z}$ and $\mathrm{AA}$ as previously described for the safety guard. Check to be sure that all units are securely fastened and operate smoothly. The assembled shearing device should look similar to the unit pictured in Fig. la, b, and c.

\section{Operation}

The mechanical shearing unit should be properly maintained and operated in a well-ventilated high light area. The unit should be placed on a solid surface at a comfortable working height. The operator should avoid loose fitting clothing, especially long-sleeved shirts, and be provided appropriate eye and ear protection devices. Some individuals can have an allergic reaction to rosemary oil. Latex-free or similar tight fitting gloves are recommended.

With the shearing unit off, place the plant to be sheared on the adjustable turntable. Adjust the turntable height and shearing unit height to achieve the desired topiary height for the sized pot on the turntable. To obtain uniformity within a crop, mark shearing unit height, jack height, and wood base (M) location. Connect power to the shearing unit.

Operator should slowly rotate the pot containing the plant on the turntable with the left hand while pressing the "on" trigger of the shearing unit with the right hand. The shearing unit will operate only while the trigger is engaged. The operator should continue to slowly rotate the plant until shearing is complete. The operator then releases the trigger and waits until the shearing blades have come to a complete stop before removing the plant from the turntable. The trimmed plant is replaced with another plant. The turntable may be adjusted to aid in plant removal and replacement, but should always be returned to the marked lo- 

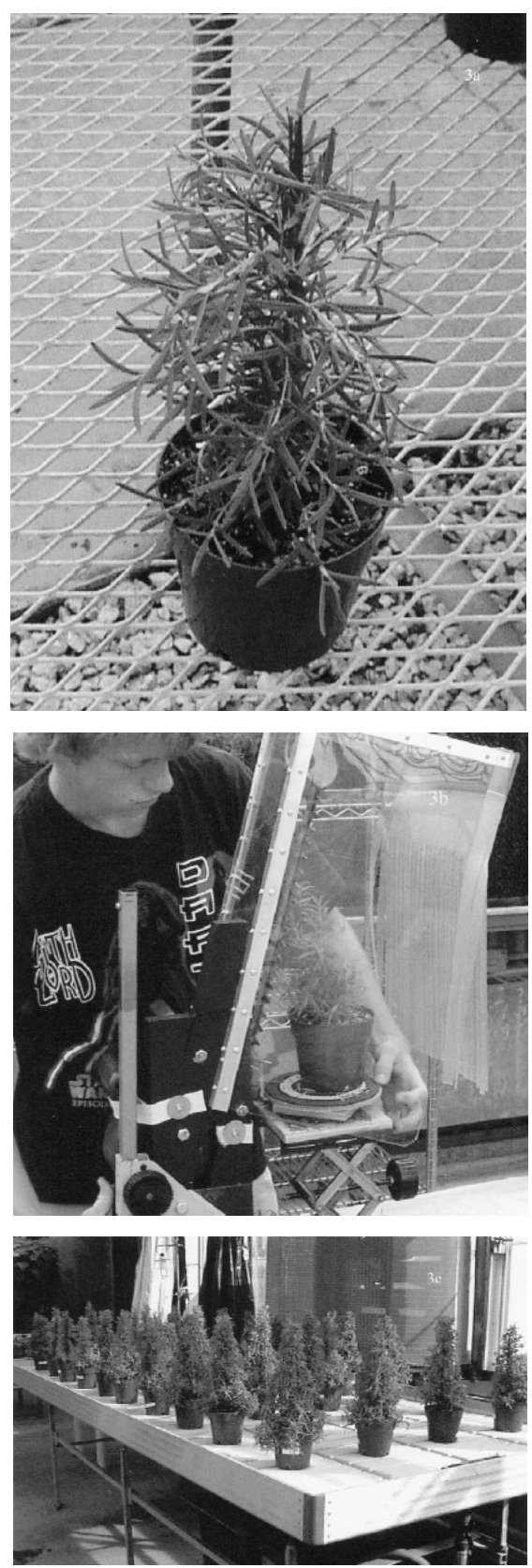

Fig. 3. Potted rosemary plants before (a) and during (b) the first trimming with the mechanical shearing device described in this manuscript and near the market ready stage $(c)$. cation before shearing the next plant. Plant debris and oil should be periodically removed. The mechanical shearing device blades should be cleaned with an organic solvent such as ethyl alcohol after each use.

On 2 July 2001, 15 rooted cuttings of an experimental rosemary cultivar numbered '302100' were transplanted into 5-inch-diameter pots filled with a soilless media (Strong-Lite Universal Mix, Seneca, Ill.). The potted plants were immediately pinched, placed in greenhouses with temperatures set at $73 / 65^{\circ} \mathrm{F}\left(22.8 / 18.3^{\circ} \mathrm{C}\right)$ day/night, and fertilized with $350 \mathrm{ppm}\left(\mathrm{mg} \cdot \mathrm{L}^{-1}\right)$ nitrogen solution in a constant liquid feed program with $20 \mathrm{~N}-4.4 \mathrm{P}-16.6 \mathrm{~K}$ (Nutriculture; Plant Marvel Laboratories, Inc., Chicago Heights, Ill.). Fertility was reduced to 100 ppm nitrogen during the last 2 months of production. To prevent flower development, plants were given a night interruption treatment using incandescent lights timed to be on from 2200 to $0300 \mathrm{HR}$ daily during the entire production cycle. Plants were randomly assigned to one of three shearing treatments; the mechanical shearing device described in this manuscript, cordless grass shears with the aid of a template, and hand shears without a template (freehand). Thus, each shearing treatment contained five plants. Beginning in August and ending in October, each plant was pruned monthly for a total of three shearing events (Fig. 3). Plant height and basal diameterwere measured weekly for 10 weeks beginning 14 Sept. 2001 immediately after the second shearing event. For each shearing technique, weekly measurements ofindividual plants were pooled to arrive at a mean height and basal diameter. The pooled weekly means were analyzed using the GLM procedure and Fisher's protected least significant difference test of the SAS System for Windows (SAS Institute, Inc., Cary, N.C.).

Table 2. Mean height (in centimeters, measured from pot base to top of plant), basal diameter (in centimeters, measured from side to side of plant base), and taper [in percentage, calculated as (basal diameter/height) $\times 100$ ] of ' 302100 ' rosemary plants shaped three times during production with one of three shearing methods.

\begin{tabular}{lccc}
\hline $\begin{array}{l}\text { Shearing } \\
\text { method }\end{array}$ & $\begin{array}{c}\text { Ht } \\
(\mathbf{c m})^{\mathrm{z}}\end{array}$ & $\begin{array}{c}\text { Basal } \\
\text { diam }(\mathbf{c m})^{\mathrm{z}}\end{array}$ & $\begin{array}{c}\text { Taper } \\
(\%)^{\mathrm{z}}\end{array}$ \\
\hline Freehand & $32.04 \pm 2.20 \mathrm{a}$ & $22.31 \pm 3.52 \mathrm{a}$ & $70.27 \pm 14.05 \mathrm{a}$ \\
Grass shears + template & $32.31 \pm 3.14 \mathrm{a}$ & $18.69 \pm 1.64 \mathrm{~b}$ & $58.04 \pm 4.64 \mathrm{~b}$ \\
Mechanical shearing device & $32.79 \pm 3.38 \mathrm{a}$ & $19.29 \pm 1.32 \mathrm{~b}$ & $59.21 \pm 5.56 \mathrm{~b}$ \\
\hline
\end{tabular}

${ }^{\mathrm{z}} 1.00 \mathrm{~cm}=0.394 \mathrm{inch}$; values are means \pm standard deviation of 10 replications (pooled mean of five plants per treatment combination measured weekly for 10 weeks during production). Means within a column followed by the same letter are not significantly different at $P \leq 0.05$ as determined by Fisher's least significant difference test.
Rosemary Christmas-tree topiaries pruned with the mechanical shearing device described in this manuscript were comparable in height, basal diameter, and taper to topiaries pruned with cordless grass shears and a template (Table 2 ). The mean tapers obtained with all three shearing methods were acceptable (Table 2). Topiaries sheared freehand, however, were less uniform than those sheared with the other devices and some pots sheared freehand greatly exceeding the $60 \%$ to $70 \%$ taper desired by the industry (Table 2). As described, the shearing device is appropriate for most rosemary topiaries grown in 4to 7 -inch-diameter pots. The described safety guard is too narrow for overgrown plants or plants in large diameter pots resulting in tipping during the shearing process. A larger safety guard and turntable should be constructed for pots exceeding 7 inches in diameter. Plant shearing should occur several times during production (De Baggio, 1987) with no more than 1 to 1.5 inch of the plant being removed at a time.

The mechanical shearing device described in this manuscript is appropriate for pruning small Christmas-treeshaped topiaries. Manufactured in less than $2 \mathrm{~d}$ from over-the-counter components, the device can be economically produced for less than $\$ 700.00$ and results in uniformly shaped topiaries with an appropriate Christmas-tree taper (Fig. 3).

\section{Literature cited}

Boelens, M.H. 1985. The essential oil from Rosemarinus officinalis L. Perfumer and Flavorist 10:21-37.

Brown, J.H., W.F. Cowen, Jr., and R.B. Heiligmann. 1991. Ohio Christmas tree producers manual. Ohio State Univ. Agr. Expt. Sta. Bul. 670.

De Baggio, T. 1987. Growing rosemary as a holiday pot plant at Christmas. Purdue Univ. Agr. Expt. Sta. Bul. 530:91-95.

Long, J. 1998. Herbs, p. 253-272. In: V. Ball (ed.). Ball redbook. 16th ed. Ball Publ., Batavia, Ill.

Sereiti, A.L., K.M. Abu-Amer, and P. Sen. 1999. Pharmacology of rosemary (Rosemarinus officinalis Linn.) and its therapeutic potentials. Indian J. Expt. Biol. 37: 124-130.

Soulier, J.M., P. Mailhebiau, P. Goeb, J.Azemar, and J. L'Hospitalier. 1996. The rosemary dossier. Cahiers de l'Aromatherapie 2:29-55.

Voigt, C.E. 2000. Rosemary, herb of the year 2000. The Herbalist 66:4-8. 